[Bull. Agr. Chem. Soc. Japan, Vol. 24, No. 1, p. 96 100, 1960]

\title{
Specific Liberation of Non Protein Nitrogen from $\kappa$-Casein Fraction by Rennin and Pepsin*
}

\author{
By Tomokichi Tsugo and Kunio Yamaughi \\ Department of Agriculttral Chemistry, Faculty of Agriculture, \\ Unitersity of Tokyo
}

Received May 18, 1959

\begin{abstract}
Liberation of non protein nitrogen during the process of rennin coagulation of casein in milk had been reported by Nitschmann et al. In this study it is shown that the non protein nitrogen was derived from $\kappa$-casein fraction mainly. Remin and pepsin liberate the non protein nitrogen from $\kappa$-casein specifically, while chymotrypsin liberates it non specifically from both $\kappa$ - and $\alpha_{R^{-}}$ caseins.
\end{abstract}

\section{INTRODUCTION}

During the primary reaction of rennin coagulation of casein in milk, the specific liberation of non protein nitrogen (12\% trichloracetic acid soluble nitrogen) has been found by Nitschmann et al. ${ }^{1-3)}$. This liberation is known to occur both in skim milk and sodium caseinate solution. Though it may not be .conclusive whether this liberation is attributed to hydrolysis of peptide bond, it seems to be certain that it is closely connected with the transformation of casein into paracasein.

Waugh and Hippel') reported the presence of a micelle stabilizing component in casein complex and designated it as $\kappa$-casein. They pointed out that this component was changed into the state of coloidal aggregate by rennin action though the detail was not yet reported.

Carinier ${ }^{51}$ obtained $\kappa$-casein fraction from $\alpha$ casein and showed that a larger quantity of non

* Studies on Milk Coagulating Enzymes. XIII.

1) C. Alais, G. Mocquot, H. Nitschmann and P. Zahler, Helv. Chim. Acta, 36, 1955 (1953).

2) H. Mattenheimer and H. Nitschmann, Helv. Cbim. Aata, 38 . $687(1955)$.

3) H. Nitschmann and H. U. Bohren. Helm. Chim. Acta, $\mathbf{3 8}$, $1953(1955)$.

4) D.F. Waugh and P. H. von Hippel, J. Am. Cbem. Sor., 78, 4576 (1956).

5) J. Carinier, Prot. Int. Symp. on Enzyme Chem., Tokyo and Kyoto 1957, p. 407. protein nitrogen (NPN) was liberated from $\kappa^{-}$ casein fraction than from true $\alpha$-casein fraction. In our previous work ${ }^{6}$, the same kind of experiment was carried out using calcium-soluble fraction (crude $\kappa$-cascin fraction) and calciuminsoluble fraction $\left(\alpha_{R}\right.$-casein ${ }^{2)}$ fraction) of Warner's $\alpha$-casein ${ }^{8)}$.

The difference of crude $\kappa$-fraction and $\alpha_{R^{*}}$ fraction in respect of NPN liberation by rennin was more distinctive than that found by $\mathrm{Ga}$ rinier. A definite amount of NPN was liberated from $\kappa$-fraction at comparatively earlier stage of rennin action, while the liberation of NPN from $\alpha_{R}$-fraction was only negligible ${ }^{*_{1}}$. Other properties such as electrophoretic mobility ${ }^{9}$, ultracentrifugal behaviour ${ }^{10}$, turbidity and ureadenaturability ${ }^{6)}$ were changed in $\kappa$-fraction by rennin but not in $\alpha_{R}$-casein. Furthermore it was demonstrated that interaction between both fractions in unseparated $\alpha$-casein was retained

6) K. Yamauchi. T. Tsugo, J. Agr. Chem. Soc. Jatath, 33, 38 (1959).

7) J. Long, Q. van Winkle and I.A. Gould, J. Datry Sci., 47, 317 (1958).

8) R.C. Warner J. Am. Chem. Sor., 66, 1725 (1944).

9) T. Tsugo and K. Yamauchi, J. Agr. Chem. Sor. Japan, 33, 35 (1959).

10) K. Yamanchi and T. Tsugo, J. Agr. Cban. Soc. Japan, $\mathbf{3 3}$ $797(1959 \%$.

$*_{1}$ It has been known recently that similar study had been reported by Wake (R. G. Wake, Australian J. Sci., 20, 147, 1957, through Chem. Abst.. 52, 6658, 1958). 
even after rennin action ${ }^{10) * 2}$. Owing to such an interaction it seems to be difficult to detect the marked change of $\kappa$-casein by rennin in unfractionated whole casein or $\alpha$-casein in calcium free system.

Long et al. " have reported recently that crude $\kappa$-casein consisted of pure $\kappa$-casein as a major component and $\lambda$-casein as a minor component. As $\kappa$-casein fraction used in the previous works contained a slow sedimenting component $(\lambda-$ casein $)^{103}$, the experiment concerning NPN liberation was repeated further using purified $\kappa$-casein. Other enzymes were also compared in this respect.

\section{EXPERIMENTAL}

\section{(1) Materials and methods}

Separation of $\alpha_{R^{*}}, \kappa^{*}$ and $\lambda$-caseins : Separation of $\alpha_{R}$-casein and crude $x$-casein has already been reported ${ }^{(3)}$. It was essentially the same as the procedure of Long et al. ${ }^{7}$ except for additional treatment of $\alpha$-casein at higher alkalinity prior to the addition of calcium chloride. The Warner's $\alpha$-casein solution was brought to about $\mathrm{pH}$ 11.0 so as to be solubilized in a monomeric state, though this treatment seems to be not necessarilly indispensable. After standing it about forty five minutes at $2^{\circ} \mathrm{C}$, it was neutralized to $\mathrm{pH} 7.0$ with $1 \mathrm{~N}$ hydrochloric acid and dialyzed against $0.085 \mathrm{M}$ sodium chloride soluticn. The dialyzate (protein concentration was $2 \sim 3 \beta_{0}$ ) was made to $0.25 \mathrm{M}$ of calcium chloride concentration by the dropwise addition of $2 \mathrm{M}$ calcium chloride at $\mathrm{pH}$ $7.0 \sim 6.6$ and allowed to stand overnight. The precipitate $\left(\alpha_{R}\right.$-fraction) was separated by centrifuging at 2,000 r.p.m. for forty minutes and washed with $0.25 \mathrm{M}$ calcium chloride. The supernatant was again centrifuged at 28,000 r.p.m. for sixty minutes in a Spinco Model L Centrifuge (No. 30 Rotor) and clear supernatant solution (crude $x$-casein fraction) was collected. It was dialyzed against distilled water repeatedly and finally against $0.085 \mathrm{M}$ sodium chloride solution. Potassium oxalate treatment was omitted because it accompanied the co-precipitation of considerable amounts of $k$-casein (about one half of total nitrogen in crude $k$-casein fraction) as pointed out by Long et al. ${ }^{7} \quad \alpha_{R}$-Casein was suspended in an adequate amount of water and dissolved by adding about $0.15 \mathrm{M}$ of solid potassium oxalate. $0.4 \mathrm{M}$

$*_{2}$ This view seems to agree with the recent study of Waugh and Gillespie (D. F. Waugh and J.M. Gillespie, Dairy Sci. Abst. $20,1032,1958)$. concentration of potassium oxalate was not adequate as it accompanied the co-precipitation of some of $\alpha_{R}$-casein as in the case of $\kappa$-casein fraction. The solubilized fraction of $\alpha_{R}$-casein was repeatedly centrifuged to remove calcium oxalate and dialyzed against distilled water and then against $0.085 \mathrm{~m}$ sodium chloride solution. Crude $r$-casein fraction was made to $\mathrm{pH} 7.0$ and to $0.2 \mathrm{M}$ with respect to sodium chloride, and then centrifuged at 40,000 r.p.m. in a Spinco Model L Centrifuge (No. 40 Rotor) for five hours at low temperature. Upper half of the supernatant (crude $\lambda$-casein fraction; sup. $B$, about $48 \mathrm{ml}$ ), lower half of the supernatant (sup. $\mathrm{C}$, about $29 \mathrm{ml}$ ) and the viscous precipitate ( $k$-casein fraction) were separated. About $0.5 \mathrm{ml}$ of top portion (sup. A) in each tube was collected from several tubes immediatly after centrifugation. Crude $\lambda$-fraction was concentrated through the celophane membrane the outer side of which was flled with carbowax $1,500^{11}$. $\alpha_{R^{*}}$, purified $k$ - and crude $\lambda$-fractions were adjusted to $\mathrm{pH}$ 6.6 with a small amount of IN sodium hydroxide after dialysis against $0.085 \mathrm{M}$ sodium chloride.

Enzymes: Referring to the method of Berridge ${ }^{123}$, rennin was purified by electrophoretic technique using Tiselius apparatus (Hitachi A Type Apparatus was used) from the extracted solution of Hansen's rennet tablets after three times salting-out with sodium chloride at pH 5.5. The purified fraction was once crystallized at pH 5.2 and lyophilized. Crystalline pepsin was a commercial product (Nutritional Biochemical Corporation) and crystalline chymotrypsin was kindly given by Miss $M$. Kondo, Instiute of Applied Microbiology, University of Tokyo. Concentration of enzyme solutions was about $0.02 \mathrm{mg} / \mathrm{ml}$ for rennin, $0.5 \mathrm{mg} / \mathrm{ml}$ for pepsin and $0.67 \mathrm{mg} / \mathrm{ml}$ for chymotrypsin respectively.

Methods : Protein concentration of each casein fraction was adjusted by dilution with suitable amounts of $0.085 \mathrm{M}$ sodium chloride solution, $0.25 \mathrm{ml}$ of the enzyme solution* was added to $5 \mathrm{ml}$ of aliquot of each fraction at $35^{\circ} \mathrm{C}$ and after a given time $5.25 \mathrm{ml}$ of $24 \%$ trichloracetic acid solution was added. After allowing to stand for about one hour, the mixture was filtered and the nitrogen in the filtrate was determined by micro $\mathrm{Kj}$ jeldahl method. The development of turbidity was traced by measuring the transmission of the reaction mixture with Coleman's Nephelometer using no flter. Phosphorus

11) K. Arai, Y. Sakaguchi and K. Nomiyama, The physito Cbemical Biology, Japan, 3, 56 (1956).

12) N.J. Berridge, Milcbwissenscbaft. 10. 195 (1955).

* With this amount of the enzymes $5 \mathrm{ml}$ of whole mili (pH 6.6) was coagulated in about six minutes by rennin, in about four minutes by pepsin and in about 7.5 minutes by chymotrypsin re spectively. 
content of each fraction was analyzed by colorimetric method after wet digestion with sulfuric acid and hydrogen peroxide ${ }^{13)}$.

(2) Phosphorus-to-nitrogen ratio of each fraction Phosphorus-to-nitrogen $(\mathrm{P} / \mathrm{N})$ ratio of all fractions described above is compared in Table I. Phosphorus-tonitrogen ratio of $\alpha_{R}$-fraction was more than twice of that of $x$-casein and almost equal to that of the top

Table I. P/N Ratio of Each Fraction of $\alpha$-CASEIN

$\begin{array}{lcr}\quad \text { Fraction } & \mathrm{P} / \mathrm{N} & \mathrm{P} \% * \\ \alpha_{R} & 0.0746 & 1.17 \\ \text { Crude } \kappa & 0.0323 & 0.51 \\ \kappa \text { (Precipit.) } & 0.0280 & 0.44 \\ \lambda \text { (Sup. A; Top portion) } & 0.0727 & 1.14 \\ \text { Crude } \lambda \text { (Sup. B ; Upper half) } & 0.0567 & 0.89 \\ \text { Sup. C (Lower half) } & 0.0420 & 0.66 \\ \text { * Calculated on the assumption that protein concentration is } \\ \quad \text { equal to N } \times 6.38 .\end{array}$

portion, which was considered to be pure $\lambda$-casein. As phosphorus-to-nitrogen ratio of the upper half portion (crude $\lambda$-casein) was considerably less than that of the top portion, it was most likely that this fraction was mixed with $\kappa$-casein. The percentage of phosphorus in Table $I$ is not a true value but only a calculated value on the assumption that protein concentration is equal to $\mathrm{N} \times 6.38$ for all fraction. The difference between phosphorus $\%$ of $\kappa$-casein in Table $I$ and that reported by Long et al. ${ }^{72}(<0.33 \%)$ is probably not a true discrepancy. Conversion factor from nitrogen to protein

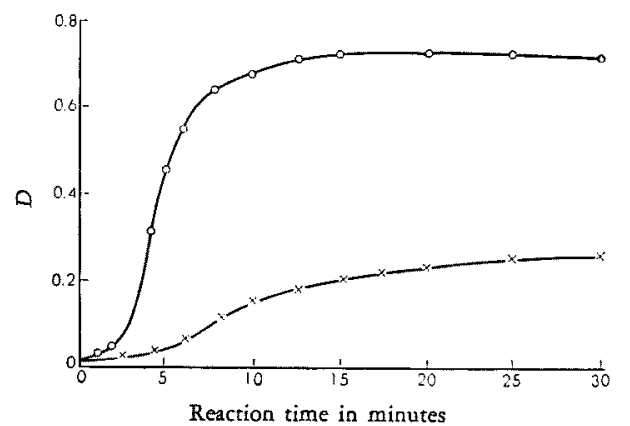

FIG. 1. Change of Transmission of $k$ - and Crude $\lambda$-Fractions by Rennin.

$$
\begin{aligned}
& \begin{array}{llcc}
\bigcirc-O & \kappa-f \text { fraction } & \text { (Protein concentration: } & 0.4 \% \text { ) } \\
\times \longrightarrow \times & \text { crude } \lambda \text {-fraction } & (1 & \text { : }
\end{array} \\
& \mathrm{D} \text {; optical density }
\end{aligned}
$$

13) M. Nakamura, J. Agr. Chem. Soc. Japan, 24. 1 (1950). concentration may be considerably higher than 6.38 in the case of $\kappa$-casein.

(3) Development of turbidity in $\kappa^{*}$ and crude $\lambda$ fractions by rennin Pertinent result is shown in Fig. 1. The development of turbidity was marked in $\kappa$ fraction. Though turbidity is developed in crude $\lambda$ fraction to some extent, it is doubtful whether it is attributed to the change of $\lambda$-casein itself.

(4) Liberation of NPN from $\kappa$-and crude $\lambda$-fractions by rennin The leberation of NPN from $\kappa$ - and crude $\lambda$-fractions is as illustrated in Fig. 2. The liberation of NPN from $\alpha_{R}$-casein was omitted as it had been already reported $^{(6)}$. It was only within $0.6 \%$ of the total nitrogen in $\alpha_{R}$-casein even after sixty minutes. The curve of purified $k$-casein in Fig. 2 was identical with that of crude $\kappa$-casein except that in purified $\kappa$-casein slightly larger amount of NPN was liberated.

(5) Comparison of rennin with pepsin and chymotrypsin The liberation of NPN from $\alpha_{R}$-fraction and $\kappa$-fraction by pepsin and chymotrypsin is shown in Fig. 3. The liberation curve of pepsin was found to resem-

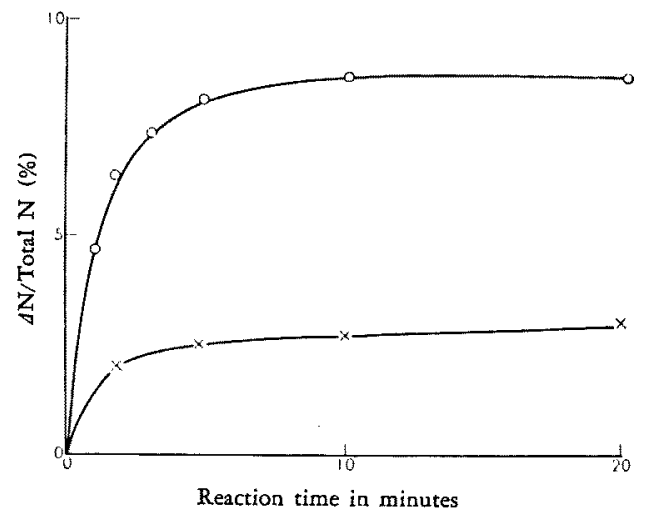

FIG. 2. Liberation of Non Protein Nitrogen (NPN) from $k$ - and Crude $\lambda$-Fractions by Rennin.

$$
\begin{gathered}
\Delta \mathrm{N} \text { Increase of non protein nitrogen (NPNt-NPNo) } \\
-\mathrm{O} \text {-fraction (protein concentration 0.4\% } \\
\text { NPNo/Total N } 4.90 \% \text { ) } \\
x-\times \quad \lambda \text {-fraction (protein concentration } 0.2 \% \\
\text { NPNo/Total N } 22.2 \% \text { ) }
\end{gathered}
$$

ble to that of rennin. Only negligible NPN was liberated from $\alpha_{R}$-fraction by pepsin as well as by rennin. Chymotrypsin showed different types of curves both for $\boldsymbol{\alpha}_{R^{-}}$ and $\kappa$-fractions.

\section{DISCUSSION}

Crude $\lambda$-fraction used in the experiments of Fig. 1 and Fig. 2 contained considerable amounts 

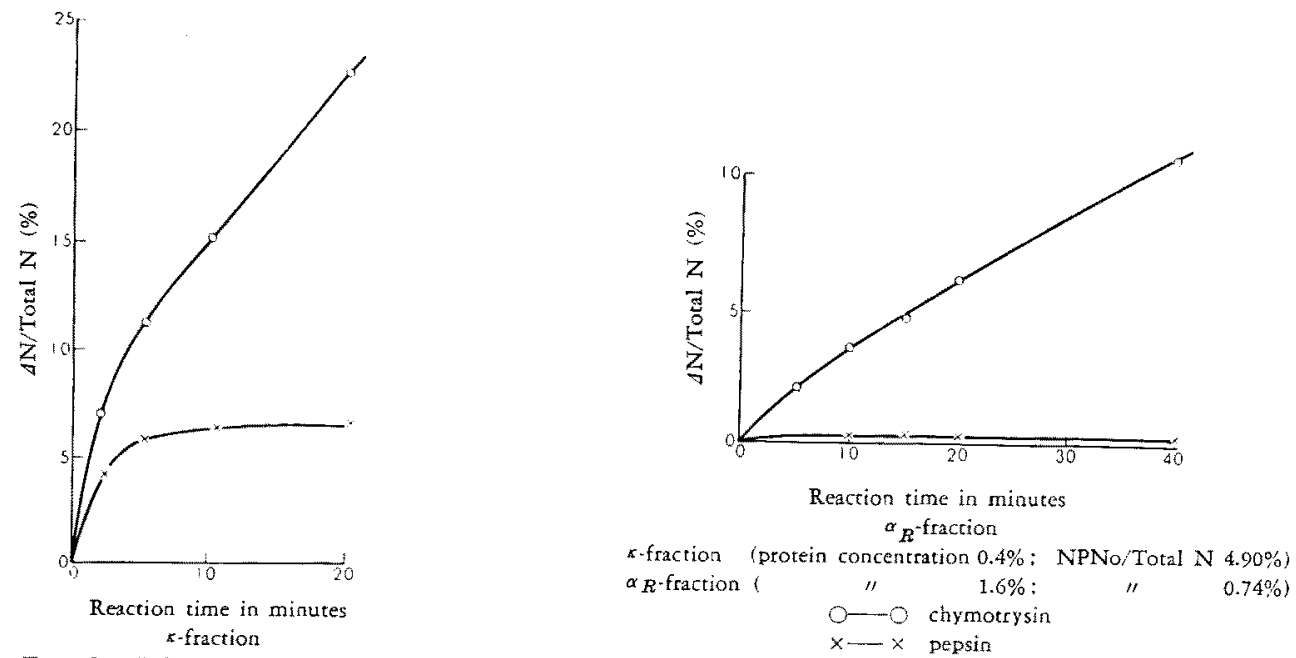

FIG. 3. Liberation of Non Protein Nitrogen from $\alpha_{R^{*}}$ and $k$-Fractions by Pepsin and Chymotrypsin.

of $\kappa$-casein as mentioned above. During separation after centrifugation, dispersion or disturbance of both fractions might occur. According to this procedure it seemed difficult to obtain pure $\lambda$-casein without considerable loss. As crude $\lambda$-fraction probably contained $\kappa$-casein, it was uncertain whether NPN was liberated from pure $\lambda$-casein by rennin. Experiments could not be carried out on the top portion because of its low yield. If phosphorus to nitrogen ratio of pure $\lambda$-casein is 0.0727 and that of pure $k$-casein is 0.028 (Table 1 ), the amount of $\kappa$-casein contained in crude $\lambda$-fraction (its phosphorus to nitrogen ratio is 0.0567 ) is calculated to be about one third of the latter\%. Since the amount of NPN liberated from crude $\lambda$-fraction was about one third of that from purified $\kappa$-fraction, it is most likely that NPN from the former was liberated from $\kappa$-casein contained in it. The development of turbidity in crude $\lambda$-fraction by rennin (Fig. 1) was also probably due to $\kappa$-casein in this fraction as turbidity was not detected when rennin was added to an aliquot of the top portion. NPN was liberated from $\kappa^{-}$

* If $x$-casein content in crude $\lambda$-fraction is $x^{*} \%, x$ will be calcu lated as follows :

$$
\begin{aligned}
0.0727(100-x)+0.028 x & =0.0567 \times 100 \\
x & =36 \%
\end{aligned}
$$

casein by rennin rapidly as the initial stage of reaction until reaching maximum value. Pepsin closely resembled to rennin in the shape of curve though the amount of NPN liberated by pepsin was slightly less than that by rennin. Liberation of NPN from $\alpha_{R}$-casein by rennin and pepsin was only negligible. Liberation of NPN from $\kappa$-casein by chymotrypsin was markedly different from that by rennin or pepsin. The shape of this curve may represent general proteolysis. NPN was markedly liberated also from $\alpha_{R}$-casein by chymotrypsin.

Comparison of yield and some properties of curds coagulated by various enzymes including rennin, pepsin and chymotrypsin has been reported by the authors ${ }^{14}$. Considerable re-solution of curd occurred in coagulation by proteases other than rennin or pepsin, while in rennin or pepsin coagulation the yield of curd was highest and re-solution did not occur. Though the change of $\kappa$-casein may be essential for the coagulation of milk by all kinds of milk coagulating enzymes, general proteolysis will occur not only in $k$-casein but also in other casein components when milk is coagulated by some enzymes other

14) T. Isugo and K. Yamauchí, Proc. XVth Int. Dairy Congr. 2, 643, Loadon, 1959 . 
than rennin or pepsin. On the contrary, rennin and pepsin are considered to have specific action on $\kappa$-casein. They will break down the structural configuration of the molecule of this component specifically accompanying the liberation of the definite amounts of NPN.

The liberation of NPN from $\kappa$-casein by rennin is assumed to be a first order reaction same as described in the report by Nitschmann et al. ${ }^{3)}$ using unfractionated casein. Furthermore, transmission curves is also possible to be expressed as a first order type reaction if $\log$

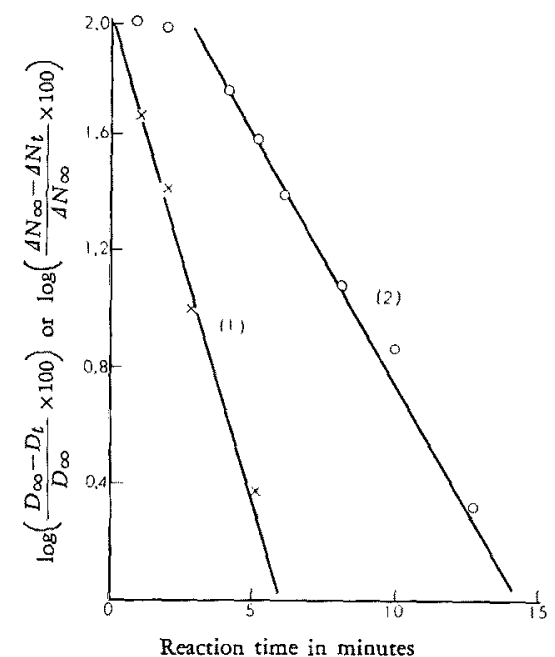

FIG. 4. Linear Expression of the Transmission Curve and NPN Liberation Curve of $\kappa$-Fraction.

(1) Liberation of NPN

(2) Transmission
$\left(\frac{D_{\infty}-D_{t}}{D_{\infty}} \times 100\right)\left(D_{\infty}\right.$ : opticol density at maximum; $D_{l}$ : optical density at $t$ minutes after rennin addition) is plotted against time, though in this case induction period at initial stage is not fitted on this line. Fig. 4 was obtained by this manner from the curves in respect of $k$ casein in Fig. 1 and Fig. 2.

\section{SUMMARY}

$\kappa$-Casein and crude $\lambda$-casein were separated from crude $\kappa$-casein (calcium soluble fraction of Warner's $\alpha$-casein). Development of turbidity and liberation of non protein nitrogen (NPN) in crude $\kappa$-casein by rennin, as already reported, was assumed to be attributed to the change of $\kappa$-casein itself.

Liberation of NPN from $\alpha_{R}$-casein (calcium insoluble fraction of Warner's $\alpha$-casein) and purified $\kappa$-casein by pepsin and chymotrypsin was compared with that by rennin. It was demonstrated that pepsin, as well as rennin, liberated a definite amount of NPN from $\kappa$ casein and scarcely liberated it from $\alpha_{R}$-casein, while chymotrypsin liberated NPN from both fractions increasingly with the increment of reaction time.

Acknowledgements The authors wish to express their sincerest thanks to Prof. Rinjiro Sasaki, Department of Agricultural Chemistry, University of Tokyo, for his kind guidance throughout this work. 